\title{
Processing and characterisation of cermet/hardmetal laminates with strong interfaces
}

\author{
F.J. Gotor ${ }^{\mathrm{a},{ }^{*}}$, R. Bermejo ${ }^{\mathrm{b}}$, J.M. Córdoba $^{\mathrm{a}}$, E. Chicardi ${ }^{\mathrm{a}}$, V. Medri ${ }^{\mathrm{c}}$, D. Dalle Fabbriche ${ }^{\mathrm{c}}$, \\ Y. Torres ${ }^{\mathrm{d}}$ \\ ${ }^{a}$ Instituto de Ciencia de Materiales de Sevilla (US-CSIC), 41092 Sevilla, Spain \\ ${ }^{\mathrm{b}}$ Institut für Struktur- und Funktionskeramik, Montanuniversität Leoben, 8700 Leoben, Austria \\ ${ }^{c}$ Institute of Science and Technology for Ceramics (CNR), 48018 Faenza, Italy \\ ${ }^{\mathrm{d}}$ Departamento de Ingeniería Mecánica y de los Materiales, E.T.S.I. (US), 41092 Sevilla, Spain
}

\begin{abstract}
Cemented carbides and cermets are potential materials for high speed machining tools. However, cemented carbides are not chemically stable at high temperature and cermets present poor fracture toughness. Novel cermet/hardmetal multilayer systems show a huge potential for this intended application. It would be possible to achieve the right balance of the required thermomechanical properties using cermet as temperature protective outer layers and hardmetal as reinforcement layers. In this work, preliminary results on the microstructural and mechanical characterisation of a multilayer $\operatorname{TiC}_{\mathrm{x}} \mathrm{N}_{1-\mathrm{x}^{-}}$ Co/WC-Co composite densified by hot pressing are presented, with special attention to the properties of the interface. Microstructural observations revealed the existence of strong bonding interfaces between cermet and hardmetal layers due to chemical interaction during the sintering process. As a consequence, owing to the different coefficient of thermal expansion between cermet and hardmetal, a tensile and compressive biaxial residual stress of $\sigma_{\text {res,Cermet }} \approx+260 \pm 50 \mathrm{MPa}$ and $\sigma_{\text {res,WC-Co }} \approx-$ $350 \pm 70 \mathrm{MPa}$ was estimated in the corresponding layers. Microindentation cracks introduced in the cermet layers (the less toughness material) and propagated
\end{abstract}


transversely to the layers were arrested at the interface, showing the combined effect of toughness and compressive stresses on crack shielding.

Keywords: cemented carbide; cermet; interface/interphase; residual stress; mechanical properties

*Corresponding autor: Instituto de Ciencia de Materiales de Sevilla (US-CSIC), Américo Vespucio, 49, 41092 Sevilla, Spain. Tel: +34 954489540, Fax: +34 954460665, email: fgotor@cica.es

\section{Introduction}

High speed machining is acquiring a great relevance as it allows not only an improvement of the superficial finishing but also a gain in productivity and a decrease of the associated cost [1]. This type of process imposes work conditions each time more extreme in terms of temperature and induced stresses, and so requires, from the corresponding cutting tools, an excellent thermo-mechanical and tribological behaviour [2]. So, the principal parameter to take into account becomes the wear produced by the high temperature reached in the cutting zone [3]. Indeed, the materials used for cutting tools design must present a set of different properties among which wear resistance, fracture toughness, hardness, mechanical reliability at high temperature, impact behaviour, chemical stability with temperature and friction coefficient can be cited as the more fundamentals ones [4].

Cemented carbides and cermets, which are actually substituting rapid steels in numerous applications, become good candidates for high speed machining tools. Cermets show a good wear and oxidation resistance, but are brittle with relatively low fracture toughness [5]. In this sense, this type of material is only used for high speed finishing but does not work under cyclic and concentrated stresses. On the other hand, cemented carbides or hardmetals have good fracture resistance, but are not chemically 
stable at high temperature, undergoing significant wear due to diffusion phenomena [6]. The only way to associate cemented carbides and high speed machining seems to be the use of ceramic coatings [7], but rather increasing exponentially the cost of the material.

Developing materials for cutting tools combining the good properties of cermets and cemented carbides remains a challenge. In this context, some authors have proposed the use of mixed $\mathrm{Ti}(\mathrm{C}, \mathrm{N})-\mathrm{WC}-\mathrm{Co}$ materials, either developing a more refractory structure in the bulk [8] or providing a graded structure [9]. More encouraging results have been obtained with the so-called functionally graded cemented carbides, characterized by a compositional gradient from the surface to the inside of the material. It is possible to obtain materials with a tough WC-Co layer at the surface [10], and also with a hard cermet surface and a tough hardmetal core [11]. In general, these materials exhibit acceptable fracture toughness in the surface (as opposed to cracking during machining) behaving in many cases better than coated cemented carbides. The key to getting the desired graded material is the precise design of the overall chemical composition and the strict control of the metallurgical reactions and the working atmosphere during sintering. However, the complexity of the phase equilibrium diagrams and metallurgical reactions involved in these functionally graded multicomponent systems often makes to achieve the desired properties and specifications difficult.

Layered ceramic materials (also referred to as "laminates") are becoming one of the most promising areas of materials technology [12]. They have been proposed as an alternative for the design of structural ceramics with improved fracture toughness, strength and mechanical reliability [13-25]. Good results have also been obtained in metal-ceramic [26] and metal-intermetallic laminates [27,28]. A key factor in the design, leading to the improvement in mechanical properties, is associated with the 
presence of compressive residual stresses in the laminate, designed with strong interfaces. Tailoring of compressive stresses and architectural design (e.g. thickness and disposition of layers) has led to an increase in fracture energy, thermal shock resistance and, in some cases, a decrease in the sensitivity of the material strength to the different size of defects, i.e. "flaw tolerant" approach [17,21,25,29-31]. The specific location of the compressive layers, either at the surface or internal, is associated with the attempted design approach, based on either mechanical resistance or damage tolerance, respectively. In the former case, the effect of the compressive residual stresses results in a higher, but single-value, apparent fracture toughness together with enhanced strength (the main goal) and some improved reliability [13,14,32]. In the latter case, the internal compressive layers are designed to act rather as a stopper to any potential crack growing from processing and/or machining flaws, at or near the surface layers such that failure tends to take place under conditions of maximum crack growth resistance $[15,17,18,21]$. The utilisation of tailored compressive residual stresses acting as physical barriers to crack propagation has succeeded in many ceramic systems, yielding in some cases a socalled "threshold strength", i.e. a minimum stress level below which the material does not fail $[15,17,21-23,33,34]$. In such layered ceramics, the strength variability of the ceramic material due to the flaw size distribution in the component is reduced, leading to an almost constant value of strength. The selection of multilayer systems with tailored compressive stresses either at the surface or in the bulk is based on the end application, and can be determined by the loading scenarios where the material will work.

In this work, preliminary results on a new class of materials with a layered design and dedicated to high speed machining tools are presented. Multilayer composites alternating 4 cermet layers and 3 hardmetal layers were fabricated and 
characterised. The outer layers presented a cermet composition, to obtain good wear resistance and oxidation resistance. The inner layers consisted of a hardmetal to act as a barrier to the propagation of cracks which may develop on the surface of the material during machining processes or in service. The disposition of the hardmetal layers was intended to generate internal compressive stresses, aiming a "flaw-tolerant" approach. The in-plane residual stress in the cermet and hardmetal layers was estimated based on classical laminate theory. The interfaces were thoroughly characterised and their mechanical behaviour was analysed based on microindentation experiments and scratch tests.

\section{Residual stresses in multilayer systems}

In every case where dissimilar materials are sealed together at high temperatures and cooled down to room temperature, they may undergo differential dimensional changes. This can be caused due to different factors: (i) intrinsic such as variations of density or volume, densification, and oxidation at the surface; or (ii) extrinsic such as thermal or thermoplastic strains developed during cooling or by external forces and momentums. Among them, the aspect most commonly referred to is the difference in the coefficients of thermal expansion (CTEs) between adjacent layers. The differences in the CTE $\left(\alpha_{\mathrm{i}}\right)$, when cooling down from sintering, may promote a differential strain between layers. As a consequence, if the interfaces of the layer materials are strong (i.e. the laminate interface does not spontaneously delaminate), an alternating tensilecompressive residual stress field is generated in the layers.

\subsection{Analytical solution}


For ideal elastic multilayer systems, neglecting the influence of the external surfaces (where stresses may relax) and considering the multilayer as an infinite plate, an analytical solution can be derived to determine the stress distribution in the layers. In an isotropic body at equilibrium under a given stress state, the stresses (i.e. $\sigma_{\mathrm{x}}, \sigma_{\mathrm{y}}, \sigma_{\mathrm{z}}$ ) may be considered resolved along three perpendicular directions $x, y$ (in-plane) and $z$ (out-of-plane). Thus, the strain in the corresponding directions (i.e. $\varepsilon_{\mathrm{x}}, \varepsilon_{\mathrm{y}}, \varepsilon_{\mathrm{z}}$ ) can be given as [35]:

$$
\begin{aligned}
& \varepsilon_{\mathrm{x}}=\frac{\sigma_{\mathrm{x}}}{E}-v \frac{\sigma_{\mathrm{y}}}{E}-v \frac{\sigma_{\mathrm{z}}}{E} \\
& \varepsilon_{\mathrm{y}}=\frac{\sigma_{\mathrm{y}}}{E}-v \frac{\sigma_{\mathrm{x}}}{E}-v \frac{\sigma_{\mathrm{z}}}{E} \\
& \varepsilon_{\mathrm{z}}=\frac{\sigma_{\mathrm{z}}}{E}-v \frac{\sigma_{\mathrm{x}}}{E}-v \frac{\sigma_{\mathrm{y}}}{E}
\end{aligned}
$$

where $E$ is the Young's modulus and $v$ the Poisson's ratio.

A particular case is that of thin layers superposed in a symmetric way, such that no stress exists in the $z$ direction (direction normal to the layer plane). Thus, $\sigma_{z}=0$, and the stresses in the $x$ and $y$ directions will be identical in the bulk, i.e. $\sigma_{\mathrm{x}}=\sigma_{\mathrm{y}}=\sigma$, leading to an equally biaxial stress state. Under these conditions, Eqs. (1), (2) and (3) will reduce to:

$$
\varepsilon_{\mathrm{x}}=\varepsilon_{\mathrm{y}}=\varepsilon=\frac{\sigma}{E}(1-v)
$$

and in general, expressed in terms of biaxial (in-plane) stress within each layer, 


$$
\sigma_{\mathrm{i}}=\frac{E_{\mathrm{i}}}{(1-v)} \cdot \varepsilon_{\mathrm{i}}=E_{\mathrm{i}}^{\prime} \cdot \varepsilon_{\mathrm{i}}
$$

where $\varepsilon_{\mathrm{i}}$ indicates the elastic strain of the $i^{\text {th }}$ layer.

For the equilibrium to exist it is required that the sum of the forces (per unit width), $F_{\mathrm{i}}$, equals to zero:

$$
\sum_{i} F_{i}=0=\sum_{i} \sigma_{i} \cdot t_{i}
$$

with $t_{i}$ being the thickness of the $i^{\text {th }}$ layer.

For a multilayer system composed of $n$ layers of composition A and thickness $t_{a}$ and $n$-1 layers of composition $\mathrm{B}$ and thickness $t_{b}$, the residual stress magnitude in each layer may be evaluated as follows:

$$
\sum_{i} \sigma_{i} t_{i}=\sum_{i} \varepsilon_{i} E_{i}^{\prime} t_{i}=\varepsilon_{\mathrm{a}} E_{\mathrm{a}}^{\prime} n t_{\mathrm{a}}+\varepsilon_{\mathrm{b}} E_{\mathrm{b}}^{\prime}(n-1) t_{\mathrm{b}}=0
$$

Defining the mismatch strain $\Delta \varepsilon$ as $\varepsilon_{\mathrm{a}}-\varepsilon_{\mathrm{b}}$, the strain in layers $\mathrm{A}$ and $\mathrm{B}$ may be rewritten as:

$$
\begin{aligned}
& \varepsilon_{\mathrm{a}}=\Delta \varepsilon \cdot \frac{E_{\mathrm{b}}^{\prime}(n-1) t_{\mathrm{b}}}{E_{\mathrm{a}}^{\prime} n t_{\mathrm{a}}+E_{\mathrm{b}}^{\prime}(n-1) t_{\mathrm{b}}} \\
& \varepsilon_{\mathrm{b}}=-\Delta \varepsilon \cdot \frac{E_{\mathrm{a}}^{\prime} n t_{\mathrm{a}}}{E_{\mathrm{a}}^{\prime} n t_{\mathrm{a}}+E_{\mathrm{b}}^{\prime}(n-1) t_{\mathrm{b}}}
\end{aligned}
$$

and solving for the corresponding stresses using Eq. (5) it holds:

$$
\sigma_{\mathrm{a}}=\Delta \varepsilon \cdot \frac{E_{\mathrm{a}}^{\prime}}{1+\frac{E_{\mathrm{a}}^{\prime} n t_{\mathrm{a}}}{E_{\mathrm{b}}^{\prime}(n-1) t_{\mathrm{b}}}}
$$




$$
\sigma_{\mathrm{b}}=-\Delta \varepsilon \cdot \frac{E_{\mathrm{b}}^{\prime}}{1+\frac{E_{\mathrm{b}}^{\prime}(n-1) t_{\mathrm{b}}}{E_{\mathrm{a}}^{\prime} n t_{\mathrm{a}}}}
$$

For the purpose of the work, the differential thermal strain is set equal to $\Delta \varepsilon=$ $\left(\alpha_{\mathrm{a}}-\alpha_{\mathrm{b}}\right) \cdot \Delta T$, where $\alpha_{\mathrm{a}}$ and $\alpha_{\mathrm{b}}$ are the CTE of A and B layers, respectively, and $\Delta T$ the temperature difference.

\section{Experimental details}

\subsection{Material of study}

WC-20 wt\%Co ( 30.6 vol\%) mixtures (hardmetal) were obtained by dry ballmilling of the blended commercially available WC $(99.5 \%$ purity, $<1 \mu \mathrm{m}$, Strem Chemicals) and Co (99.9\% purity, <100 mesh, Sigma) powders for $1 \mathrm{~h}$ in a planetary mill (Pulverisette 7, Fritsch) using hardened steel jar and balls. $\mathrm{TiC}_{0.5} \mathrm{~N}_{0.5}-20$ wt $\% \mathrm{Co}$ ( 12.7 vol\%) mixtures (cermet) were obtained by the mechanochemical process denoted as mechanically induced self-sustaining reaction (MSR) from elemental powder mixtures of Ti (99\% purity, < 325 mesh, Strem Chemicals), C (graphite, $<270$ mesh, Fe $\leq 0.4 \%$, Merck) and Co (99.8\% purity, < 100 mesh, Strem Chemicals). The MSR process was carried out in the planetary mill under a nitrogen atmosphere. This method takes advantage of the strong exothermic character of the carbonitride formation to promote self-propagating reactions during milling. The details of this synthesis can be found elsewhere [36].

Symmetrical laminates of 7 layers were fabricated from these mixtures alternating 4 cermet and 3 hardmetal layers, with an alternated sequence and $\sim 1: 1$ thickness ratio. The laminates were molded using a uniaxial press. The layers were stacked one after the other from loose powders into a hardened stainless steel die with 
an internal diameter of $45 \mathrm{~mm}$, and a pressure of $10 \mathrm{MPa}$ was applied after each layer. The green body was subsequently hot pressed in an induction-heated graphite die at $1300{ }^{\circ} \mathrm{C}$ (heating rate of $20{ }^{\circ} \mathrm{C} / \mathrm{min}$ and free cooling) with an applied pressure of 20 $\mathrm{MPa}$ and holding time of $3 \mathrm{~min}$ in low vacuum $(\sim 100 \mathrm{~Pa})$. To avoid debonding problems and lack of adhesion, as a result of thermo-elastic mismatch between the adjacent layers, the pressure was maintained during the cooling step. The sintered laminates were then cut perpendicularly to the layers with diamond wheels and carefully ground and mirror polished for characterisation.

\subsection{Structural and microstructural characterisation}

The crystalline phases were identified by X-ray diffraction (XRD) on polished surfaces using a PANalytical X'Pert PRO instrument equipped with a $\Theta / \Theta$ goniometer, a $\mathrm{Cu} \mathrm{K} \alpha$ radiation source $(40 \mathrm{kV}, 40 \mathrm{~mA})$, a secondary $\mathrm{K} \beta$ filter and an $\mathrm{X}^{\prime}$ Celerator detector. The diffraction patterns were obtained by scanning from 20 to $140^{\circ}(2 \theta)$ in the step-scan mode with $0.02^{\circ}$ steps and a counting time of 275 s/step. The microstructure was analysed by scanning electron microscopy (SEM) using a Hitachi S- 4800 SEMField Emission Gun microscope. The transition metal contents in the ceramic and binder phases were measured using an energy dispersive X-ray spectrometry (EDS) detector (Bruker) coupled to the SEM.

\subsection{Mechanical characterisation}

Indentation tests were performed at different loads in the range 100-1000 N using a Vickers diamond pyramidal indenter (EMCO TEST M4U-025) on different locations of the polished surfaces of the laminates to study the behaviour of each individual layer and specially the interface between them. Loads of $1000 \mathrm{~N}$ were able to 
generate cracks that initiated in the cermet layer, propagating perpendicularly to the layers through the material interface toward the tougher hardmetal layer. The effect of the layered architecture on the indentation crack propagation was studied. The size of the indentations, as well as the length and the crack path were characterised using a Nikon Epiphot optical microscope (OM) coupled to a Jenoptik Progress C3 camera and the SEM microscope. The hardness and the crack growth resistance were evaluated in each layer material.

A commercial scratch tester (Microtest MTR3/50-50/NI.) with a detector for acoustic emission (AE) and a built-in optical microscope were used to study the layer adhesion. The scratch length was $4 \mathrm{~mm}$. During testing a $200 \mu \mathrm{m}$ radius Rockwell C diamond stylus was dragged across the laminated surface under different normal constant loads of 5, 10 and $15 \mathrm{~N}$. The normal load is continuously recorded during scratching. Sliding contact response was given in terms of scratch penetration-load curves. The corresponding friction coefficient was also computed through the normal and tangential force, both measured by a strain-gauge type dynamometer. The microscratch scars were examined by OM and SEM in order to discern the contact damage feature at the interface and within each layer of the laminate.

\section{Results and discussion}

In previous work [37], it was shown that cermets developed by MSR contain TiCo intermetallic compounds instead of cobalt as the binder phase. The presence of these brittle intermetallic compounds in the binder induces that these cermets exhibit low fracture toughness values (4-5 $\mathrm{MPam}^{1 / 2}$ ). For this reason, these cermets were chosen to develop the laminates, so that they were composed of brittle cermet layers and tough 
hardmetal layers, with the aim of extracting more easily the benefits of a multilayer structure.

On the other hand, in previous pressureless sintering experiments, problems of adhesion and delamination were observed probably due to the different values of CTE [38] for WC and $\mathrm{TiC}_{0.5} \mathrm{~N}_{0.5}\left(5.8 \times 10^{-6}\right.$ and $8.4 \times 10^{-6}{ }^{\circ} \mathrm{C}^{-1}$, respectively). For this reason, the CTE value for each individual layer was adjusted by modifying the Co content (CTE of $13.0 \times 10^{-6}{ }^{\circ} \mathrm{C}^{-1}$ ) to obtain layers with theoretically (as calculated by the rule of mixtures) no excessive differences in CTE $\left(9.0 \pm 0.1 \times 10^{-6} \mathrm{C}^{-1}\right.$ and $8.0 \pm 0.1 \times 10^{-6} \mathrm{C}^{-1}$ for cermet and hardmetal, respectively). This together with the use of assisted pressure sintering methods was crucial to prevent the delamination of the sintered laminates.

\subsection{Microstructural and phase analysis}

Figure 1 shows the XRD pattern of the laminates after sintering, where the reflexions corresponding to the ceramic $\mathrm{TiC}_{0.5} \mathrm{~N}_{0.5}$ and $\mathrm{WC}$ phases are clearly visible. The presence of $\mathrm{Co}$, the binder phase in the hardmetal layer, and $\mathrm{TiCo}$ and $\mathrm{TiCo}_{2}$ intermetallics, the expected binder phases in the cermet layer, are also observed in the XRD pattern. A shift to higher $2 \theta$ values was observed in Co XRD peaks presumably due to the presence of $\mathrm{W}$ dissolved in the Co structure. Other small peaks were visible in Figure 1 that were associated with the presence of $\mathrm{Co}_{3} \mathrm{~W}_{3} \mathrm{C}$ and $\mathrm{Co}_{6} \mathrm{~W}_{6} \mathrm{C}$ phases that probably formed during the sintering process. However, the low intensity of these XRD peaks makes this assignment uncertain.

Figure 2 shows a low magnification SEM micrograph of the laminate crosssection comprising four layers of cermet (dark contrast) and three layers of hardmetal (bright contrast). The mean thickness value for each layer was $\sim 1 \mathrm{~mm}$. However, although the two types of layers were well defined, the resulting interlayers were not 
straight probably due to imperfect shaping of the layers in the green body and the use of pressure during sintering. As a result, the thickness of some of the layers was not constant over the entire sample. Figure 2 also evidenced a good densification of the cermet layer, whereas the porosity in the hardmetal layer was significantly higher likely to be a consequence of too low sintering temperature and/or time. In fact, the cermet mixture obtained by the mechanochemical process is more prone to densification because of a higher surface activity and free energy. Regarding the structural integrity of the multilayer after sintering, no cracks were found in the hardmetal and cermet layers. The presence of the so-called "edge cracks" and "tunnelling cracks" (see for instance $[39,40])$, i.e. cracks running parallel or perpendicular to the layers respectively, was not observed.

The cermet and hardmetal layers interacted during the sintering process despite the low sintering temperature and short dwell time employed, producing at the interface a heterostructure composed of different phases extending for 40-50 $\mu \mathrm{m}$ (Fig. 3). This interaction generated a strong interface that was helpful to avoid spontaneous cracks in the interlayer. A careful study based on elemental mapping and point chemical analysis using EDS on SEM was performed at the interface to semi-quantitatively determine the distribution of all relevant elements ( $\mathrm{Ti}, \mathrm{W}$ and $\mathrm{Co})$ and identify the chemical nature of phases. These analyses were also useful to figure out the metallurgical reactions involved during sintering. Figure 4 shows representative EDS mappings of the different regions observed in the cermet/hardmetal interface (Fig. 3). The labels in Figure 4 correspond to the regions marked in Figure 3. Elemental compositions (at\%) at discrete points in the interface being representative of the different phases as observed by SEM were calculated and presented in Table I. The typical zones analysed are marked with numbers in Figure 4 and Table I. Each composition corresponds to the average of at 
least 5 different measurements. The relatively large standard deviation observed for some chemical compositions is due to the fine scale of the microstructure and hence the interference from neighbouring phases.

In the cermet layer far away from the interface, the microstructure was characterised by $\operatorname{Ti}(\mathrm{C}, \mathrm{N})$ ceramic particles with a bimodal size distribution (small rounded and large faceted particles) embedded in the binder phase (Fig. 4a). As the interface is approached (Fig. 4b), the formation of the typical core-rim microstructure was observed, resulting from the precipitation of a carbonitride solid solution phase containing $\mathrm{Ti}$ and $\mathrm{W},(\mathrm{Ti}, \mathrm{W})(\mathrm{C}, \mathrm{N})$, onto the original $\mathrm{Ti}(\mathrm{C}, \mathrm{N})$ particles. The EDS analysis and mapping carried out in this region of the interface corroborated the presence of $\mathrm{W}$ in the rim (zone 1 in Table I), but not in the core (Fig. 4b). The presence of this core-rim microstructure is evidence that there was chemical interaction between adjacent layers and also revealed the migration of $\mathrm{W}$ dissolved in the molten binder from the hardmetal layer towards the cermet layer. The different Co volume content, $30.6 \mathrm{vol} \%$ and $12.7 \mathrm{vol} \%$ in the hardmetal and cermet layers, respectively, was the driving force for the molten binder migration during sintering, as frequently observed during the fabrication of functionally graded cemented carbides [41].

After this region characterised by the core-rim microstructure, a large area with a higher volume fraction of binder and small rounded ceramic particles was observed. In this region, the binder showed two different contrasts; a dark grey contrast in the zone close to the cermet layer side and a light grey contrast close to the hardmetal layer side (Fig. 4c). The EDS mapping showed the presence of Co, Ti and W in both of them, but with a different $\mathrm{W}$ and Ti content ratio (zone 2 and 3 in Table I). The $\mathrm{W}$ content was obviously lower in the binder zone with dark contrast. EDS analysis performed on the ceramic particles present in this region showed that they were also composed of a 
$(\mathrm{Ti}, \mathrm{W})(\mathrm{C}, \mathrm{N})$ carbonitride solid solution, but with a chemical composition richer in $\mathrm{W}$ than the rim phase previously mentioned. The presence of these ceramic particles with a typical rim composition evidenced a homogeneous precipitation from the molten binder containing Ti and $\mathrm{W}$ coming from the dissolution of $\mathrm{WC}$ and $\mathrm{Ti}(\mathrm{C}, \mathrm{N})$ original particles [42].

After this binder-rich region, a clear barrier constituted by ceramic particles was observed in the interface close to the hardmetal layer (Fig. 4d). EDS analysis confirmed that this barrier had also a chemical composition characteristic of a rim phase. The high W content observed (zone 4 in Table I) was the result of precipitation from a binder with a high amount of W. After this barrier, an area practically depleted of WC particles was observed (Fig. 4d) consisting of elemental Co and a phase containing mainly Co and $\mathrm{W}$ (zone 5 in Table I) and probably $\mathrm{C}\left(\right.$ see $\mathrm{Co}_{3} \mathrm{~W}_{3} \mathrm{C}$ and $\mathrm{Co}_{6} \mathrm{~W}_{6} \mathrm{C}$ phases in Figure 1). Finally, the characteristic hardmetal microstructure composed of small faceted WC particles surrounded by Co was observed (Fig. 4e).

In summary, the migration from the hardmetal layer to the cermet layer of the molten binder containing $\mathrm{Co}$ and $\mathrm{W}$ and its interaction with the molten binder containing Co and Ti generated a complex interface composed of binder phases with a gradient chemical composition in $\mathrm{W}$ and $\mathrm{Ti}$ and $(\mathrm{Ti}, \mathrm{W})(\mathrm{C}, \mathrm{N})$ ceramic particles that homogeneously precipitated. The liquid phase migration leaving behind these ceramic particles could have created the observed ceramic barrier. The interface can be defined then as the region where the simultaneous presence of $\mathrm{Ti}$ and $\mathrm{W}$ is detected in the binder.

\subsection{Mechanical characterisation of layers and interfaces}


Figure 5 shows the indentation marks performed at $1000 \mathrm{~N}$ in the centre of the cermet and hardmetal layers. Indentation within the cermet layer caused symmetrical cracks emanating from the corner of the mark, which was a clear indication of the brittle nature of the layer. In contrast, no cracks were observed in the tough hardmetal layer. The different size of indentation marks reflected the different hardness of layers, being approximately 14.6 GPa and 5.5 GPa for the cermet and hardmetal layers, respectively. The high hardness of the cermet layers was due to the presence of intermetallic compounds and the low hardness of the hardmetal layers to porosity.

In Figure 6a, it can be seen more clearly as long indentation cracks propagated longitudinally to the cermet layer, whereas transverse cracks were significantly shortened because they stopped in the hardmetal layer. Figure $6 \mathrm{~b}$ shows the transverse crack penetrating through the interface, propagating straight without any noticeable deflection, and arresting once the hardmetal layer was reached. Additionally, indentation tests were also performed to assess the brittleness of the interfaces. Vickers indentations were introduced with the corners of the imprint located at the interface between layers, as shown in Fig. 7. Cracks emanating from the corner of the imprint located in the cermet layer were observed. However, no cracks were found in the hardmetal layer. Only very small cracks (marked with arrows in Fig. 7) were generated at the interface. This indicates that the interface is strong, and that the fracture toughness of the interfaces is higher than the toughness of the cermet layer. In some cases, indentation lateral cracks were observed in the cermet layers, associated with the tensile residual stresses in these layers.

Scratch tests were also performed to study the bonding between adjacent layers. The penetration depth measured at a constant load of $15 \mathrm{~N}$ is given in Figure 8. Figure 9 shows an example of the scratch grooves produced during the scratch test. The smooth 
and shallow tracks confirmed that the laminate has densified properly during sintering. The different width of the scratch scars in the cermet and hardmetal layers was the result of different hardness. There is a clear change in the depth of penetration when the scratch is inside or outside the hardmetal layer because of the removal and drag of the cobalt binder phase with lower hardness. At all evaluated loads, a good adhesion between layers was observed without any damage at the interface, confirming the existence of strong bonding. Spallation or formation of cracks was not observed.

\subsection{Estimation of residual stresses in the cermet/hardmetal multilayer}

According to Eqs. (10) and (11), the magnitude of residual stresses in the interior of the cermet and cemented carbide layers can be estimated, based on the properties of each layer material and layer thicknesses. The elastic constants (i.e. $E$ and v) and CTE are the key parameters. The elastic properties of the cermet and hardmetal layers were taken from measurements on bulk specimens: $E_{\mathrm{WC}-\mathrm{Co}}=433 \mathrm{GPa}, v_{\mathrm{WC}-\mathrm{Co}}=$ $0.26, \alpha_{\mathrm{WC}-\mathrm{Co}}=8.0 \pm 0.1 \times 10^{-6} \mathrm{C}^{-1} ; E_{\mathrm{Cermet}}=266 \mathrm{GPa}, v_{\mathrm{Cermet}}=0.31, \alpha_{\mathrm{Cermet}}=9.0 \pm 0.1 \times 10^{-}$ ${ }^{6} \mathrm{C}^{-1} . \Delta \varepsilon$ can be calculated as:

$$
\Delta \varepsilon=\left(\alpha_{\text {Cermet }}-\alpha_{\text {WC-C }_{\mathrm{o}}}\right) \Delta T
$$

$\Delta T$ is $T_{\mathrm{Ref}}-T_{0}$, and in our case, the reference temperature $T_{\operatorname{Ref}}$ was assumed to be the sintering temperature, i.e. $1300{ }^{\circ} \mathrm{C}^{\gamma}$, and $T_{0}$ was the room temperature. According to the material properties of each layer, a tensile and compressive biaxial residual stress of $\sigma_{\text {res,Cermet }} \approx+260 \pm 50 \mathrm{MPa}$ and $\sigma_{\text {res,WC-Co }} \approx-350 \pm 70 \mathrm{MPa}$ was estimated in the cermet and hardmetal layers, respectively.

\footnotetext{
${ }^{\gamma}$ Due to the high content of Co in the hardmetal layers, relaxation might occur down to a temperature of the order of $800^{\circ} \mathrm{C}$. However, since it has not been measured experimentally, $1300{ }^{\circ} \mathrm{C}$ was considered as the reference temperature for the residual stress estimation.
} 
4.4. Guidelines for cermet/hardmetal multilayer designs with improved mechanical behaviour

The multilayer design presented in this investigation has shown strong interfaces between cermet and hardmetal layers. Accordingly, compressive stresses in the order of $-350 \mathrm{MPa}$ may be generated in the internal hardmetal layers. This compressive stresses can be beneficial against crack propagation, as reported in literature for oxide ceramics (e.g. alumina-zirconia systems). However, relatively high tensile stress in the cermet layers (i.e. +260MPa) might damage the structural integrity of these layers. As a consequence tunnelling cracks or surface cracks might be generated upon cooling down from sintering, even before service (see for instance [39]).

A way to reduce the magnitude of tensile residual stresses in the cermet layers can be inferred from Eq. (6). The equilibrium condition implies that the stresses in the cermet and hardmetal layers must be counterbalanced. Thus:

$$
\sigma_{\text {cermet }}=-\sigma_{W C-C o} \cdot \frac{(n-1) \cdot t_{W C-C o}}{n \cdot t_{\text {cermet }}}
$$

with $n$ being the total number of layers. From this basic formula a qualitative analysis can be extracted taking into account the thickness of the layers. If $t_{W C-C o} \ll t_{\text {cermet }}$ then $\sigma_{\text {cermet }} \rightarrow 0$, i.e. if thin hardmetal layers are inserted between thick cermet ones, the tensile stresses inside the latter will be reduced. Thus, tensile stresses in the cermet layers can be lowered by increasing the volume ratio between cermet and hardmetal layer material (i.e. $V_{\text {cermet }} / V_{W C-C o}$ or $\left.n \cdot t_{\text {cermet }} /(\mathrm{n}-1) \cdot t_{W C-C o}\right)$. This allows fabrication of multilayer systems with high internal compressive stresses in thin layers combined with 
thick layers exhibiting low tensile residual stresses, whose effect on the final strength of the material may not be significant.

An additional key parameter in the design of multilayer systems is the location of the internal compressive layers with respect to the potential loaded surface. It has been recently demonstrated that maximum crack growth resistance can be achieved in designs which have thin (tensile) outer layers (in our case the cermet layer) followed by a relatively thicker compressive layer (in this case the WC-Co layer), see [25] for more details. In future work, multilayer designs with strong interfaces combining layers with different volume ratios will be attempted in order to investigate the thermo-mechanical behaviour of this new class of cermet/hardmetal multilayer systems.

\section{Conclusions}

Symmetric laminates composed of hard brittle cermet layers and tough hardmetal layers were fabricated by hot press sintering. During sintering, strongbonding interfaces were generated between adjacent layers driven by the migration of the molten binder from the hardmetal layer toward the cermet layer. The formation of the core-rim microstructure in the cermet region near the interface and the formation of a ceramic barrier near the hardmetal layer were clear evidence of the migration of the binder phase. The interaction between two Co-rich molten binders, one containing $\mathrm{W}$ dissolved and the other $\mathrm{Ti}$, generated a heterogeneous interface characterised by a binder with gradient chemical composition, from which ceramic particles composed by a carbonitride solid solution precipitated.

Indentation tests performed in the layers and at the interfaces revealed tough hardmetal layers (indentation cracks were arrested at the hardmetal layer) and relatively 
brittle cermet layers (4-5 times longer cracks propagating parallel to the cermet layer plane). The interfaces were strong, as characterised by scratch test which did not produce any damage in the interlayer zone. No interface damage was observed. An estimation of biaxial residual stresses in the layers indicated relatively high compressive stresses in the hardmetal layers (i.e. $\sigma_{\text {res,WC-Co }} \approx-350 \pm 70 \mathrm{MPa}$ ) and high tensile stresses in the cermet layers (i.e. $\sigma_{\text {res,Cermet }} \approx+260 \pm 50 \mathrm{MPa}$ ). Although compressive stresses in the hardmetal layers can be beneficial for mechanical behaviour, tensile stresses in the cermet layers should be reduced. Guidelines for cermet/hardmetal multilayer designs are proposed, which opens a potential development of a new class of materials for highspeed machining with better thermo-mechanical equilibrium.

\section{Acknowledgments}

This work was supported by the Spanish government under grant No. MAT2011-22981 and the Junta de Andalucía under grant No. P12-TEP-2622, which were financed in part by the European Regional Development Fund of 2007-2013. E. Chicardi and J. M. Córdoba were supported by the CSIC through JAE-Pre and JAE-Doc grants, respectively, which are financed in part by the European Social Fund (ESF). The authors want to thank the laboratory technician J. Pinto for its assistance with mechanical testing. 


\section{References}

[1] Dawes RC, Aspinwall DK. A review of ultra high speed milling of hardened steels. J Mater Process Technol 1997;69(1-3):1-17.

[2] Dolinšek S, Šuštaršič B, Kopač J. Wear mechanisms of cutting tools in high-speed cutting processes. Wear 2001;250(1-12):349-356.

[3] Abukhshim NA, Mativenga PT, Sheikh MA. Heat generation and temperature prediction in metal cutting: A review and implications for high speed machining. Int $\mathbf{J}$ Mach Tools Manuf 2006;46(7-8):782-800.

[4] Ezugwu EO, Bonney J, Yamane Y. An overview of the machinability of aeroengine alloys. J Mater Process Technol 2003;134(2):233-253.

[5] Ettmayer P, Kolaska H, Lengauer W, Dreyer K. Ti(C,N) cermets-Metallurgy and properties. Int J Refract Met Hard Mat 1995;13(6):343-351.

[6] List G, Nouari M, Géhin D, Gomez S, Manaud JP, Le Petitcorps Y, Girot F. Wear behaviour of cemented carbide tools in dry machining of aluminium alloy. Wear 2005;259(7-12):1177-1189.

[7] Beake BD, Fox-Rabinovich GS, Veldhuis SC, Goodes SR. Coating optimisation for high speed machining with advanced nanomechanical test methods. Surf Coat Technol 2009;203(13):1919-1925.

[8] Mondal B, Das PK, Singh SK. Advanced WC-Co cermet composites with reinforcement of TiCN prepared by extended thermal plasma route. Mat Sci Eng A 2008;498(1-2):59-64.

[9] Tsuda K, Ikegaya A, Isobe K, Kitagawa N, Nomura T. Development of functionally graded sintered hard materials. Powder Metall 1996;39(4):296-300. 
[10] Bolognini S, Mari D, Viatte T, Benoit W. Fracture toughness of coated TiCNWC-Co cermets with graded composition. Int J Refract Met Hard Mat 2001;19(46):285-292.

[11] Chen L, Lengauer W, Dreyer K. Advances in modern nitrogen-containing hardmetals and cermets. Int J Refract Met Hard Mat 2000;18(2-3):153-161.

[12] Bermejo R, Deluca M. Layered ceramics. In: Somiya S, Kaneno M, editors. Handbook of Advanced Ceramics, 2nd edition. Tokyo: Academic Press, 2012. p. 733751.

[13] Lakshminarayanan R, Shetty DK, Cutler RA. Toughening of layered ceramic composites with residual surface compression. J Am Ceram Soc 1996;79(1):79-87.

[14] Green DJ, Tandon R, Sglavo VM. Crack arrest and multiple cracking in glass through the use of designed residual stress profiles. Science 1999;283:1295-1297.

[15] Rao M, Sanchez-Herencia J, Beltz G, McMeeking RM, Lange F. Laminar ceramics that exhibit a threshold strength. Science 1999;286:102-105.

[16] Rao MP, Rödel J, Lange FF. Residual stress induced R-curves in laminar ceramics that exhibit a threshold strength. J Am Ceram Soc 2001;84(11):2722-2724.

[17] Lugovy M, Slyunyayev V, Subbotin V, Orlovskaya N, Gogotsi G. Crack arrest in $\mathrm{Si}_{3} \mathrm{~N}_{4}$-based layered composites with residual stress. Comp Sci Tech 2004;64:19471957.

[18] Sglavo VM, Paternoster M, Bertoldi M. Tailored residual stresses in high reliability alumina-mullite ceramic laminates. J Am Ceram Soc 2005;88(10):2826-2832.

[19] Bermejo R, Torres Y, Sanchez-Herencia AJ, Baudin C, Anglada M, Llanes L. Residual stresses, strength and toughness of laminates with different layer thickness ratios. Acta Mater 2006;54(18):4745-4757. 
[20] Zhang X, Zhou P, Hu P, Han W. Toughening of laminated $\mathrm{ZrB}_{2}$-SiC ceramics with residual surface compression. J Eur Ceram Soc 2011;31(13):2415-2423.

[21] Bermejo R, Torres Y, Baudin C, Sánchez-Herencia AJ, Pascual J, Anglada M, Llanes L. Threshold strength evaluation on an $\mathrm{Al}_{2} \mathrm{O}_{3}-\mathrm{ZrO}_{2}$ multilayered system. J Eur Ceram Soc 2007;27(2-3):1443-1448.

[22] Bermejo R, Torres Y, Anglada M, Llanes L. Fatigue behavior of alumina-zirconia multilayered ceramics. J Am Ceram Soc 2008;91(5):1618-1625.

[23] Bermejo R, Pascual J, Lube T, Danzer R. Optimal strength and toughness of $\mathrm{Al}_{2} \mathrm{O}_{3}-\mathrm{ZrO}_{2}$ laminates designed with external or internal compressive layers. $\mathrm{J}$ Eur Ceram Soc 2008;28(8):1575-1583.

[24] Fang Y, Zhang Y, Song J, Fan H, Hu L. Design and fabrication of laminatedgraded zirconia self-lubricating composites. Mater Des 2013;49:421-425.

[25] Sestakova L, Bermejo R, Chlup Z, Danzer R. Strategies for fracture toughness, strength and reliability optimisation of ceramic-ceramic laminates. Int $\mathrm{J}$ Mat Res 2011;102(6):613-626.

[26] Shi G, Wu Z, Wang Z, Liang J. The mechanical properties and microstructure of the bionic alloy-ceramic laminated composite. Mater Des 2012;33:300-305.

[27] Durejko T, Lipinski S, Bojar Z, Bystrzycki J. Processing and characterization of graded metal/intermetallic materials: The example of Fe/FeAl intermetallics. Mater Des 2011;32:2827-2834.

[28] Bataev IA, Bataev AA, Mali VI, Pavliukova DV. Structural and mechanical properties of metallic-intermetallic laminate composites produced by explosive welding and annealing. Mater Des 2012;35:225-234. 
[29] Bermejo R, Llanes L, Anglada M, Supancic P, Lube T. Thermal shock behavior of an $\mathrm{Al}_{2} \mathrm{O}_{3} / \mathrm{ZrO}_{2}$ multilayered ceramic with residual stresses due to phase transformations. Key Eng Mat 2005;290:191-198.

[30] Lube T, Pascual J, Chalvet F, De Portu G. Effective fracture toughness in $\mathrm{Al}_{2} \mathrm{O}_{3}-$ $\mathrm{Al}_{2} \mathrm{O}_{3} / \mathrm{ZrO}_{2}$ laminates. J Eur Ceram Soc 2007;27(2-3):1449-1453.

[31] Bermejo R, Danzer R. High failure resistance layered ceramics using crack bifurcation and interface delamination as reinforcement mechanisms. Eng Fract Mech 2010;77(11):2126-2135.

[32] Hansen JJ, Cutler RA, Shetty DK, Virkar AV. Indentation Fracture Response and Damage Resistance of $\mathrm{A} 12 \mathrm{O} 3-\mathrm{ZrO} 2$ Composites Strengthened by TransformationInduced Residual Stresses. J Am Ceram Soc 1988;71(12):C501-C505.

[33] Lugovy M, Slyunyayev V, Orlovskaya N, Blugan G, Kuebler J, Lewis M. Apparent fracture toughness of $\mathrm{Si}_{3} \mathrm{~N}_{4}$-based laminates with residual compressive or tensile stresses in surface layers. Acta Mater 2005;53(2):289-296.

[34] Sglavo VM, Bertoldi M. Design and production of ceramic laminates with high mechanical resistance and reliability. Acta Mater 2006;54(18):4929-4937.

[35] Timoshenko SP, Goodier JN. Theory of elasticity. $3^{\text {rd }}$ ed. New York: Mc-GrawHill; 1970.

[36] Córdoba JM, Alcalá MD, Avilés MA, Sayagués MJ, Gotor FJ. New production of $\mathrm{TiC}_{\mathrm{x}} \mathrm{N}_{1-\mathrm{x}}$-based cermets by one step mechanically induced self-sustaining reaction: Powder synthesis and pressureless sintering. J Eur Ceram Soc 2008;28(10):2085-2098.

[37] Chicardi E, Torres Y, Córdoba JM, Hvizdoš P, Gotor FJ. Effect of tantalum content on the microstructure and mechanical behavior of cermets based on $\left(\mathrm{Ti}_{\mathrm{x}} \mathrm{Ta}_{1-\mathrm{x}}\right)\left(\mathrm{C}_{0.5} \mathrm{~N}_{0.5}\right)$ solid solutions. Mater Des 2014;53:435-444. 
[38] Gladysz GM, Chawla KK. Coefficients of thermal expansion of some laminated ceramic composites. Composites: Part A 2001;32(2):173-178.

[39] Ho S, Hillman C, Lange FF, Suo Z. Surface cracking in layers under biaxial, residual compressive stress. J Am Ceram Soc 1995;78(9):2353-2359.

[40] Bermejo R, Sanchez-Herencia AJ, Baudin C, Llanes L. Residual stresses in $\mathrm{Al}_{2} \mathrm{O}_{3^{-}}$ $\mathrm{ZrO}_{2}$ multilayered ceramics: nature, evaluation and influence on the structural integrity. Bol Soc Esp Ceram V 2006;45(5):352-357.

[41] Fan P, Fang ZZ, Guo J. A review of liquid phase migration and methods for fabrication of functionally graded cemented tungsten carbide. Int J Refract Met Hard Mat 2013;36:2-9.

[42] Bellosi A, Medri V, Monteverde F. Processing and properties of Ti(C,N)-WCbased materials. J Am Ceram Soc 2001;84(11):2669-2676. 


\section{Figure captions}

Figure 1. XRD pattern of the cermet/hardmetal laminate after hot press sintering.

Figure 2. SEM micrograph showing the laminate structure.

Figure 3. SEM micrograph of the interface between cermet and hardmetal layers. The interface region has been divided into approximate zones a) to f) showing different microstructural features.

Figure 4. Characteristic EDS mappings of the different regions observed in the interface of adjacent layers. Labels correspond to regions marked in Figure 3 and numbers to elemental analysis shown in Table I.

Figure 5. OM micrographs of indentation marks performed at $1000 \mathrm{~N}$ in the centre of the (a) cermet and (b) hardmetal layers.

Figure 6. (a) SEM micrograph of the indentation mark performed at $1000 \mathrm{~N}$ in the centre of the cermet showing the different length of perpendicular and transversal indentation cracks. (b) Detail of the transversal crack arresting at the interface.

Figure 7. SEM micrographs of indentation marks performed at $1000 \mathrm{~N}$ localised in the interlayer region. In (b), chipping observed in the brittle cermet layer that arrest at the interface.

Figure 8. Penetration depth-load response in unidirectional sliding at a constant load of $15 \mathrm{~N}$

Figure 9. SEM micrographs of scratch tracks performed at $15 \mathrm{~N}$ showing good adhesion between layers and the good integrity of the interface after testing. 
Table I. Point chemical EDS analysis performed in different zones at the interface between cermet and hardmetal layers. Numbers in Figure 4 marks the zones analysed.

\begin{tabular}{clccc}
\hline Zone & Description & Ti (at.\%) & W (at.\%) & Co (at.\%) \\
\hline 1 & Rim phase & $95.6 \pm 1.1$ & $4.4 \pm 1.1$ & - \\
2 & Dark binder & $25.3 \pm 3.0$ & $9.5 \pm 1.3$ & $65.2 \pm 3.3$ \\
3 & Bright binder & $11.3 \pm 2.9$ & $31.1 \pm 3.2$ & $57.6 \pm 1.8$ \\
4 & Ceramic barrier & $88.5 \pm 0.9$ & $11.5 \pm 0.9$ & - \\
5 & WC depleted zone & $5.0 \pm 1.3$ & $41.4 \pm 2.0$ & $53.6 \pm 3.2$ \\
\hline
\end{tabular}




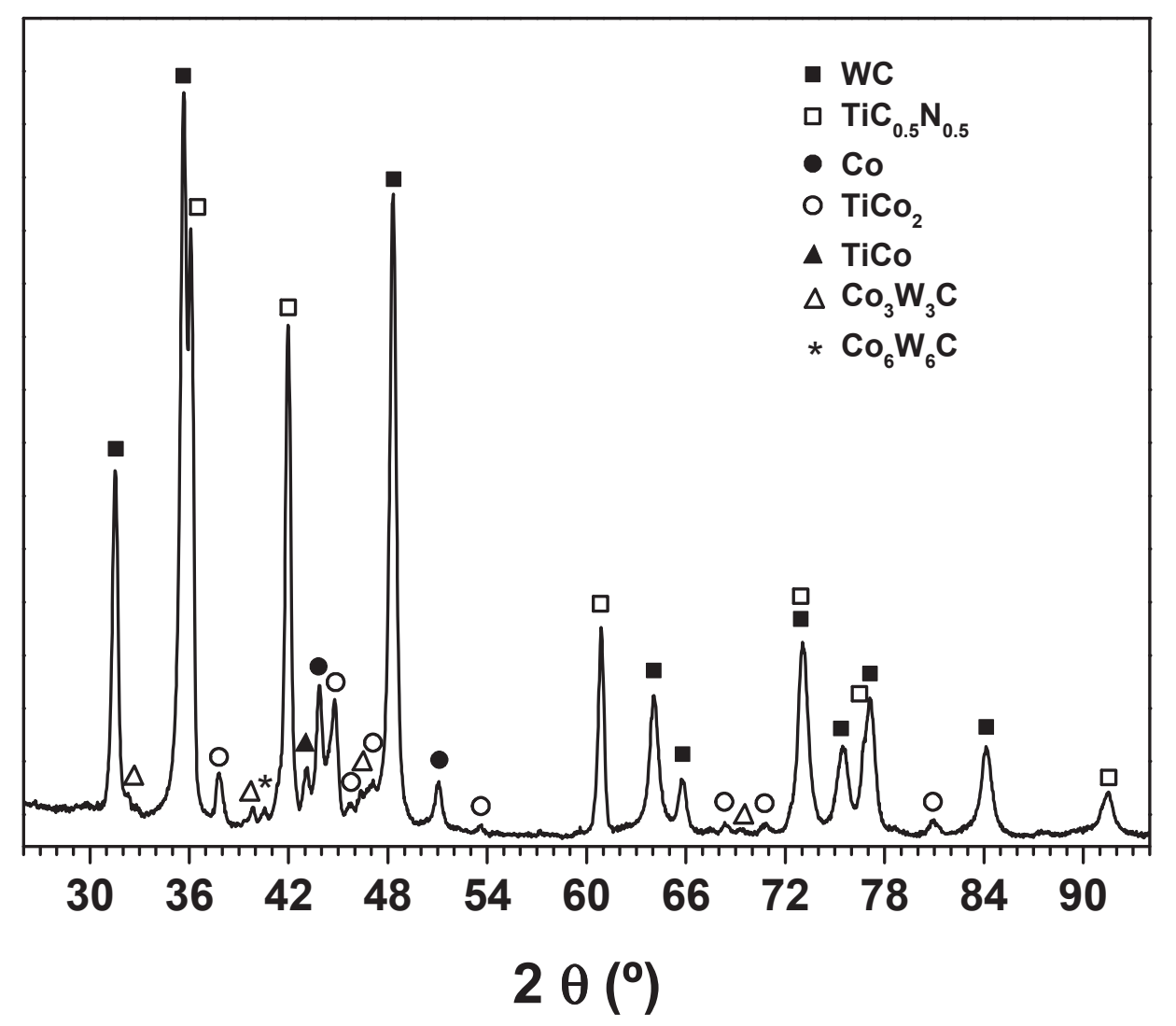

FIGURE 1 


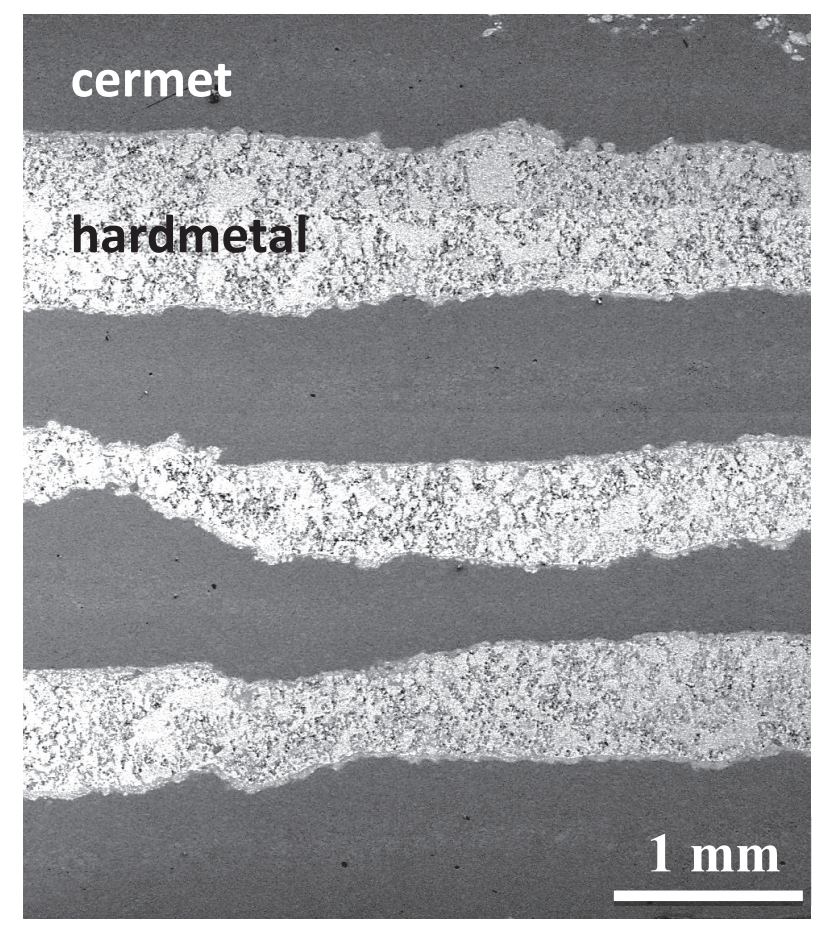

FIGURE 2 


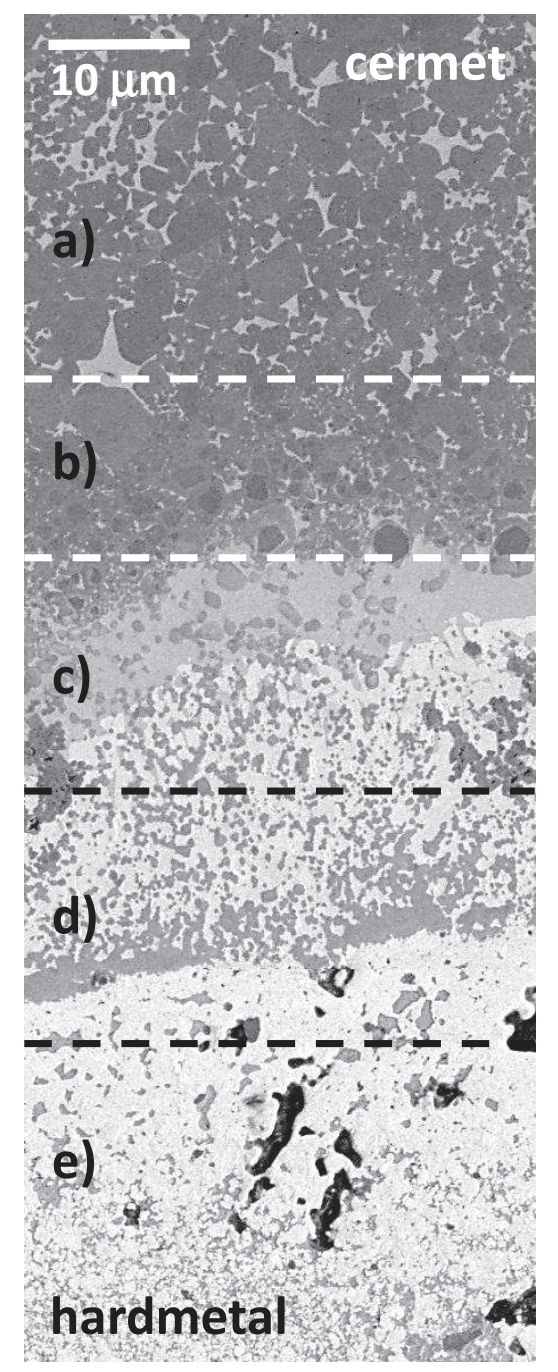

FIGURE 3 


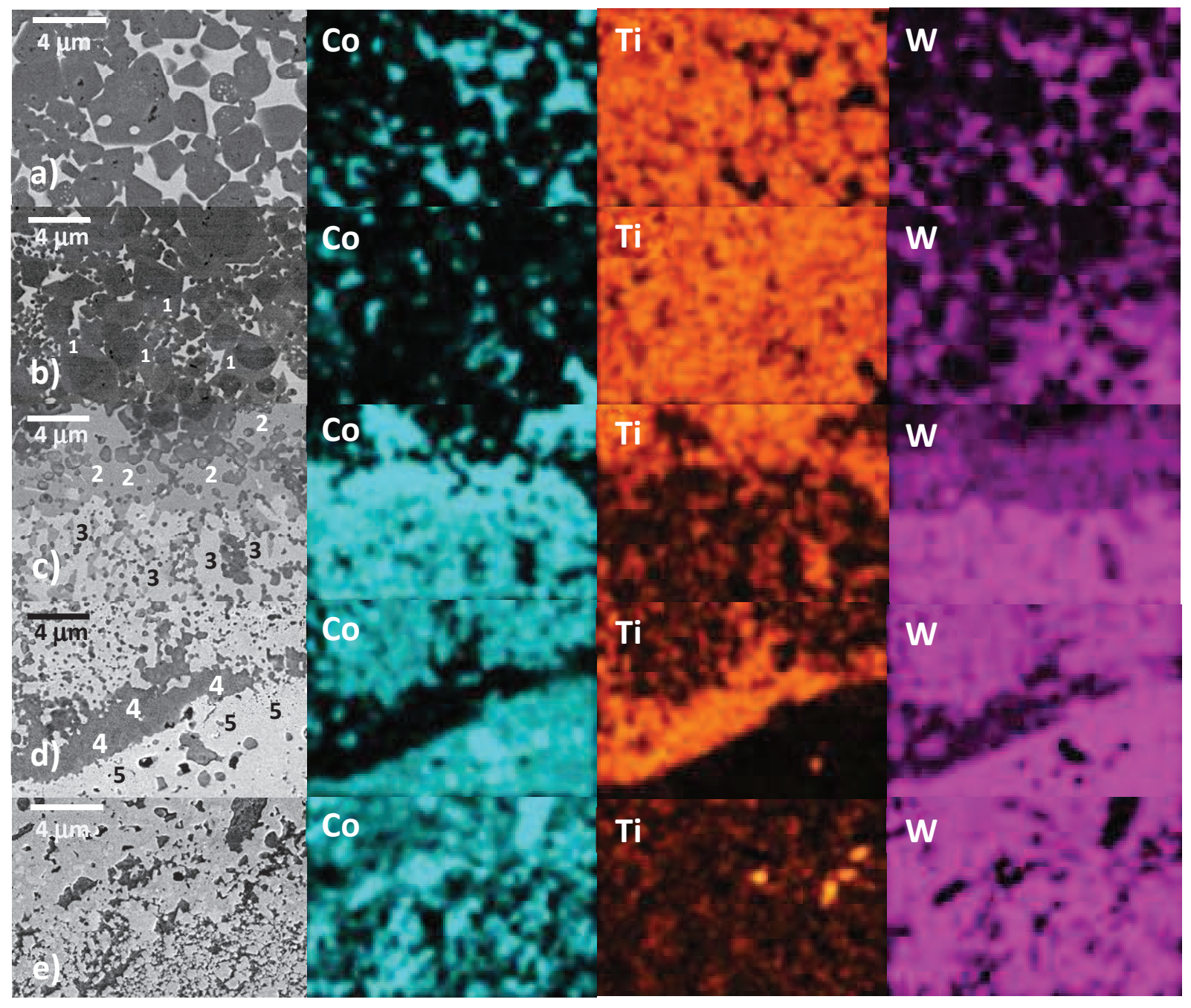

FIGURE 4 


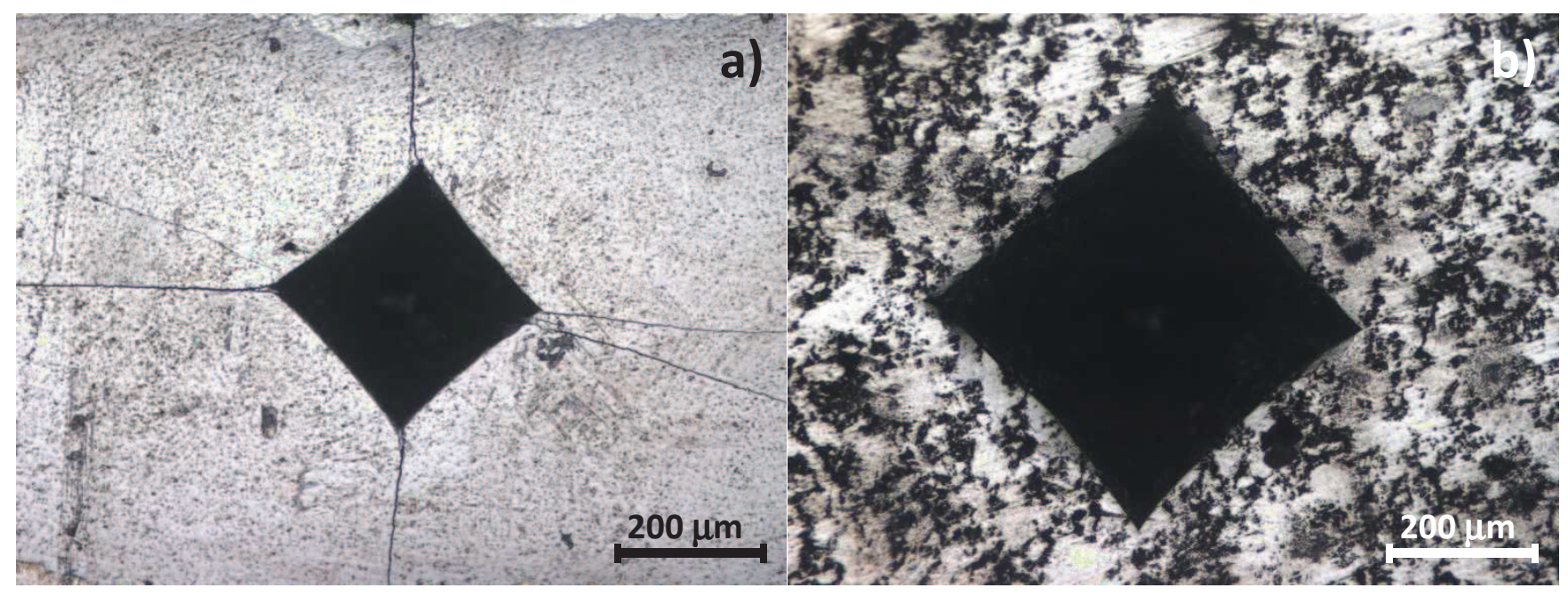

FIGURE 5 


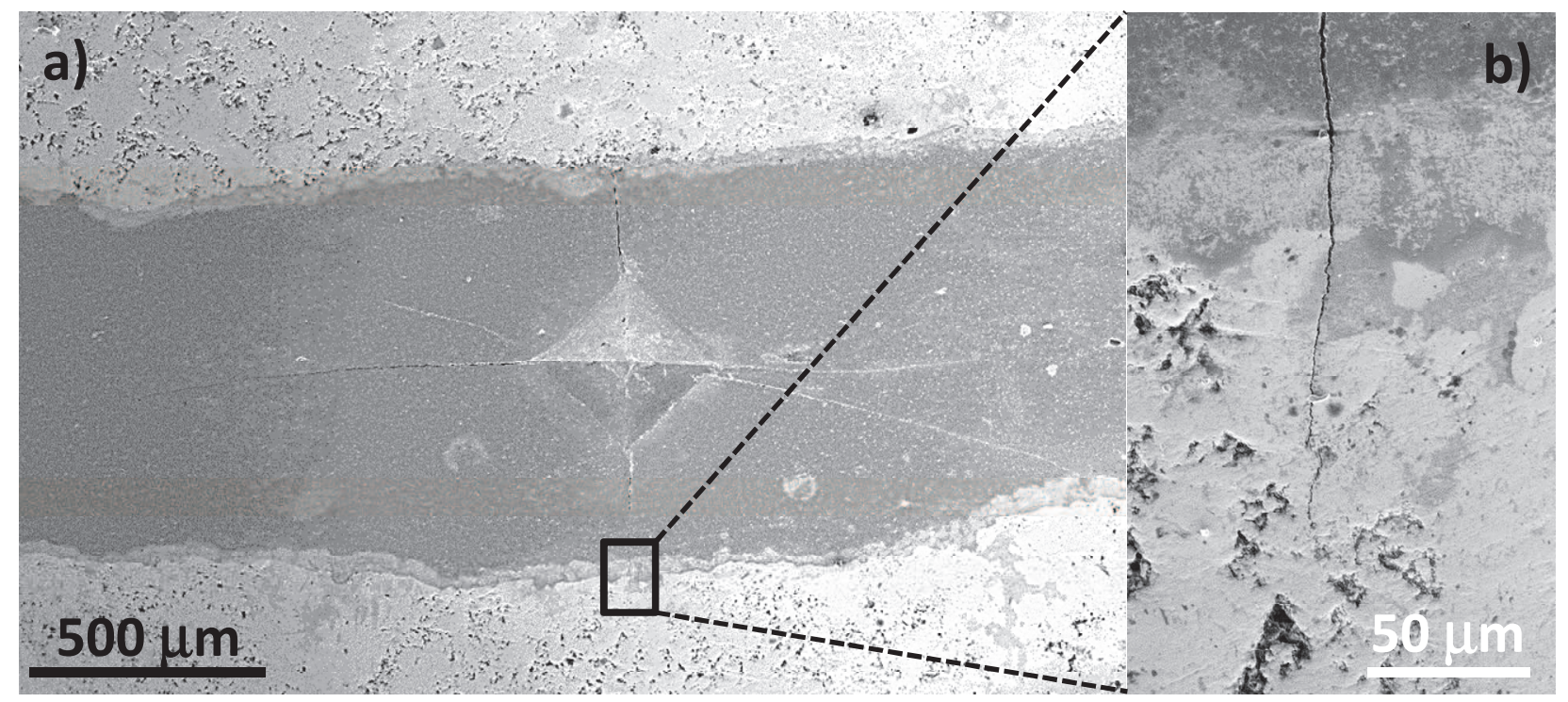

FIGURE 6 


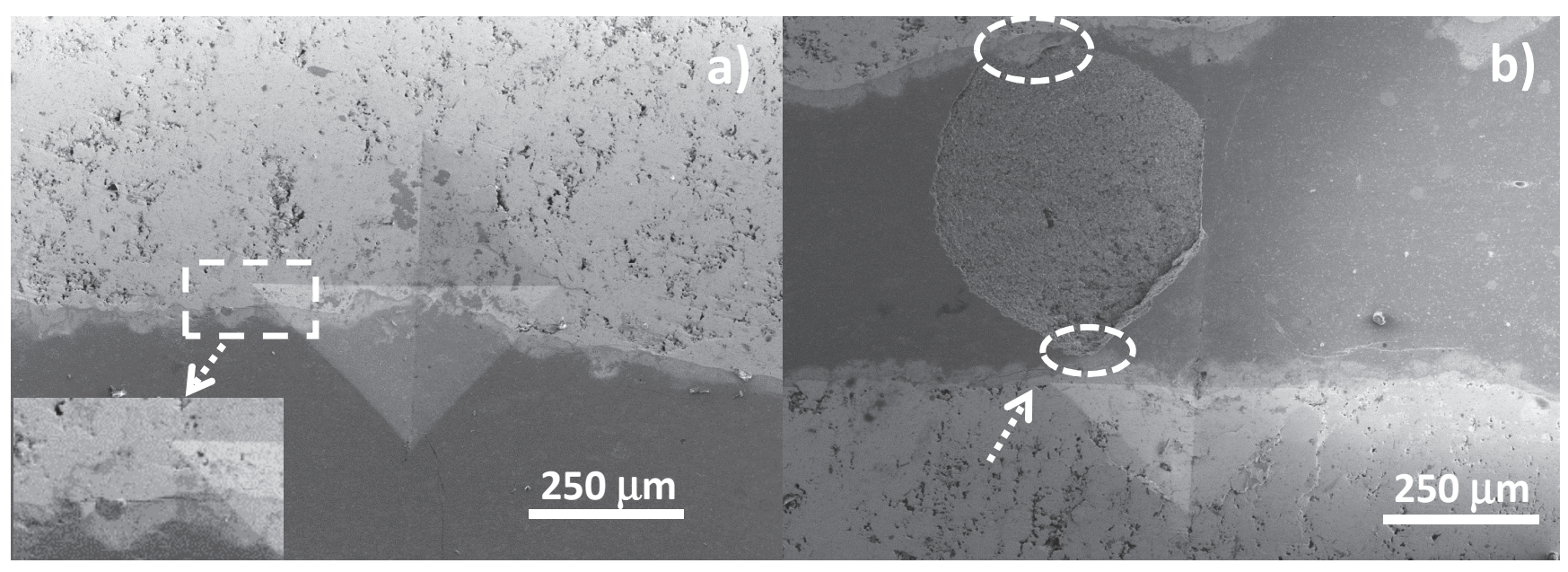

FIGURE 7 


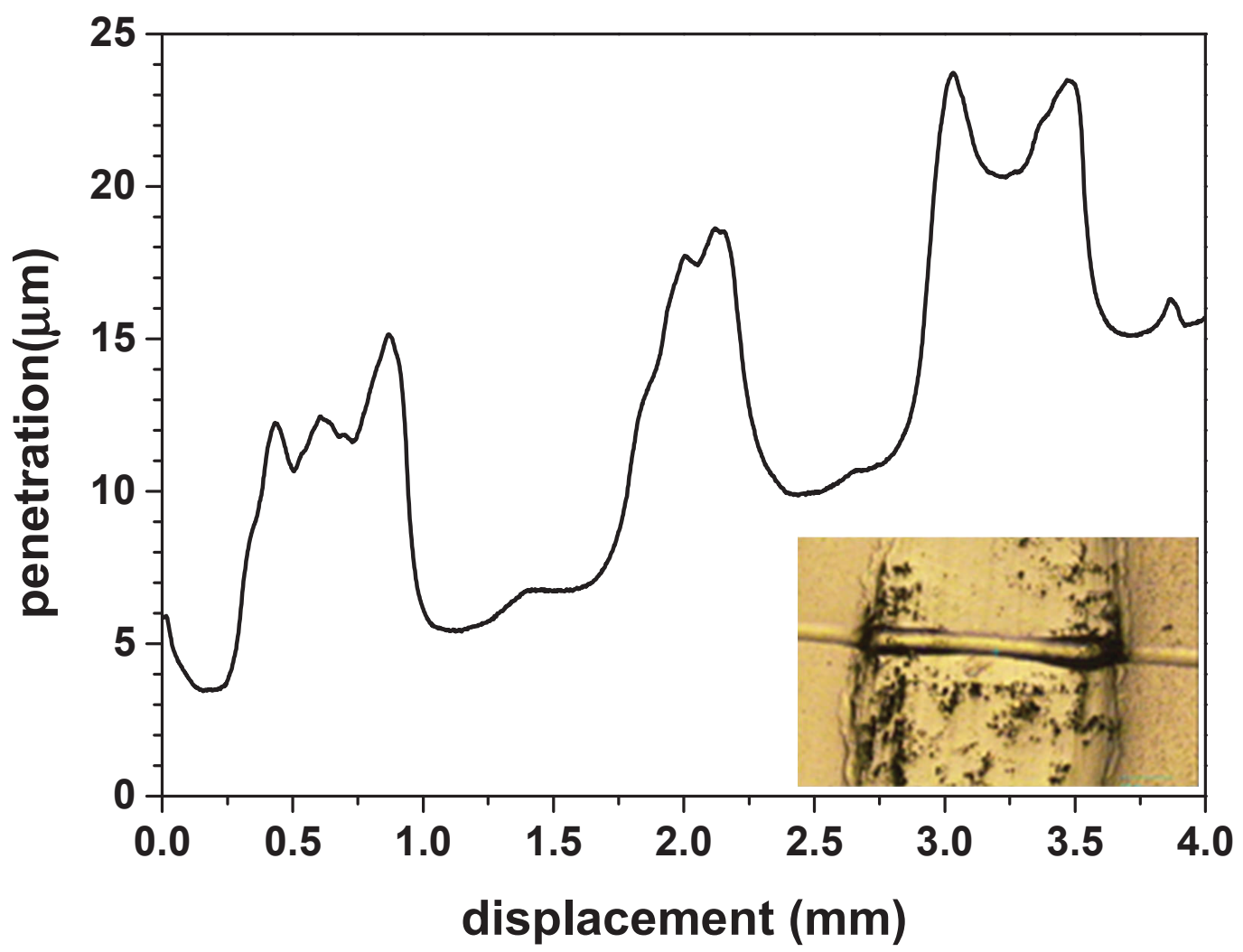

FIGURE 8 


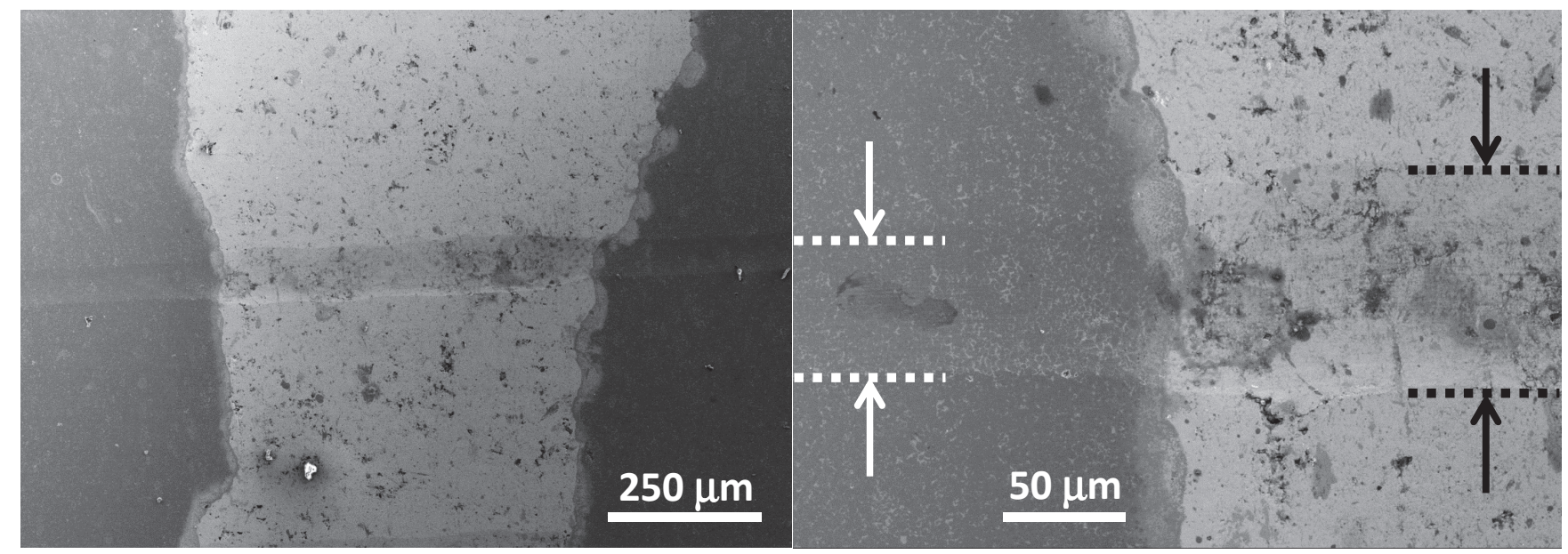

FIGURE 9 